\title{
Output Architecture of the Primate Putamen
}

\author{
Alice W. Flaherty ${ }^{1,2}$ and Ann M. Graybiel' \\ 'Department of Brain and Cognitive Sciences, Massachusetts Institute of Technology, Cambridge, Massachusetts 02139 \\ and ${ }^{2}$ Division of Health Sciences and Technology, Harvard Medical School, Boston, Massachusetts 02115
}

The basal ganglia act through direct and indirect striatopallidal output pathways that have different effects on cortical activity. This division has been proposed to underlie the fundamental distinction between hyperkinetic and hypokinetic movement disorders such as Parkinson's disease and Huntington's disease. Evidence to date does not favor a relationship between this dual organization and the division of the striatum into striosome and matrix compartments. However, the possibility has been raised that the division of striatopallidal output paths reflects a compartmentalization of the matrix itself into clusters of different striatopallidal projection neurons. We directly tested this hypothesis in squirrel monkeys by comparing the distributions of striatal output neurons retrogradely labeled from the two pallidal segments. Striatopallidal neurons labeled by small injections confined to either the external pallidum (GPe) or the internal pallidum (GPi) formed small clusters ("matrisomes") in the matrix compartment of the putamen. However, contrary to previous predictions, labeled matrisomes projecting to GPe were not systematically separated from those projecting to GPi. They could overlap extensively, and within individual matrisomes GPe-projecting neurons and GPi-projecting neurons were extensively intermixed. Double-retrograde labeling analysis in single sections demonstrated that only 2.1 $\pm \mathbf{2 . 7} \%$ of labeled striatal neurons were doubly labeled from both GPe and GPi-a number not significantly different from zero. GPe-projecting and GPi-projecting neurons in the putamen also differed sharply in their expression of enkephalin-like immunoreactivity: $71.3 \pm 7.6 \%$ of the neurons labeled by GPe injections were enkephalin positive, in contrast to only $\mathbf{1 0 . 0} \pm \mathbf{3 . 6} \%$ of the neurons labeled by GPi injections.

These results suggest that in the primate, populations of striatopallidal output neurons are grouped in clusters in the matrix, but that individual neurons in any given cluster project either to GPe or to GPi. Matrisomal clustering may thus coordinate signals sent into the direct and indirect pathways of the basal ganglia from distributed populations of projection neurons in the striatum.

[Key words: basal ganglia, primate, putamen, globus pallidus, motor systems, enkephalin, retrograde tracers, Parkinson's disease, Huntington's disease, population coding]

Received Nov. 23, 1992; revised Feb. 15, 1993; accepted Feb. 18, 1993.

We thank H. F. Hall, who is responsible for the photography, and C. L. Shneider and G. Holm for their help with manuscript processing. This work was funded by Javits Award NIH RO1NS25529 and the Human Frontier Science Program.

Correspondence should be addressed to Ann M. Graybiel, Department of Brain and Cognitive Sciences, Building E25, Room 618, 45 Carleton Street, Cambridge, MA 02139.

Copyright (C) 1993 Society for Neuroscience $0270-6474 / 93 / 133222-16 \$ 05.00 / 0$
The control of movement by the basal ganglia depends in part on the activity of two striatopallidal circuits that appear to have different effects on motor activity. The "direct" pathway from the striatum through the internal pallidum (GPi) and the substantia nigra pars reticulata ( $\mathrm{SNr}$ ) may facilitate movement by activating thalamocortical circuits through a doubly inhibitory release mechanism. The "indirect" pathway from the striatum through the external pallidum (GPe) may inhibit movement by modulating this disinhibitory drive (for review, see Crossman, 1987; Albin et al., 1989; Alexander and Crutcher, 1990). Targeting certain striatal outputs to GPe and others to GPi-or keeping these outputs linked - could therefore influence whether movements occur and how. Such a targeting device for movement control by the striatum should be strongly represented in the putamen, which contains most movement-related neurons of the striatum except those related to eye movements (IIikosaka et al., 1989). Because the putamen is the principle region of the striatum processing direct inputs from the sensory and motor cortex, and the primary source of input to the pallidum, the putamen could serve as a key switching station directing sensorimotor inputs to GPe and to GPi.

There is controversy, however, over the degree to which striatal neurons projecting to GPe are separate from those projecting to GPi. On the one hand, GPe-projecting neurons have been differentiated from those projecting to GPi (and to the $\mathrm{SNr}$ ) by their neurochemistry. Both sets of neurons are GABAergic, but striatal axon terminals in GPe tend to express enkephalin-like neuropeptides as cotransmitters, whereas striatal terminals in GPi and SNr tend to coexpress substance Plike and dynorphin-like neuropeptides. Evidence obtained in the rat suggests that these neurons also differ in their proportional expression of $D_{1}$-like and $D_{2}$-like dopamine receptor mRNAs (Gerfen et al., 1990; Le Moine et al., 1990; MeadorWoodruff et al., 1991) and in their transcriptional responses to direct and indirect dopamine agonist stimulation (Berretta et al., 1992; Zhang et al., 1992). On the other hand, the segregation of transmitter-related substances is far from complete: some neurons express enkephalin-like as well as substance P-like peptides, and $D_{1}$ receptor $m R N A s$ as well as $D_{2}$ receptor mRNAs and binding sites (Penny et al., 1986; Besson et al., 1990; Meador-Woodruff et al., 1991; Surmeier et al., 1992; Ariano et al., 1992). It is not known whether neurons that coexpress these molecules also project to both GPe and GPi/SNr, or whether such coexpression, reported for the rat and cat, occurs in the primate. Estimates of the number of striatal output neurons sending collaterals to more than one target nucleus have varied widely-from very few to the proposal that all neurons projecting to SN also project to GP (Bolam et al., 1981; Feger and Crossman, 1984; Loopuijt and van der Kooy, 1985; Beckstead 
and Cruz, 1986; Parent et al., 1989; Giménez-Amaya and Graybiel, 1990; Kawaguchi et al., 1990; Selemon and GoldmanRakic, 1990).

In primates and cats, striatal projection neurons are organized in macroscopic clusters that can be labeled by injections of retrograde tracers into the pallidum or the $\mathrm{SNr}$ (Desban et al., 1989; Jiménez-Castellanos and Graybiel, 1989; Giménez-Amaya and Graybiel, 1990, 1991; Selemon and Goldman-Rakic, 1990). The clusters are not striosomes; they lie in the extrastriosomal matrix. For this reason, they have been called matrisomes (Graybiel et al., 1991). It has been proposed that the targeting of striatal information to GPe and GPi may be organized at the level of these clusters (Divac, 1984; Feger and Crossman, 1984; Giménez-Amaya and Graybiel, 1990, 1991; Selemon and Goldman-Rakic, 1990). Experiments so far have tested this proposal only indirectly. The idea is appealing because it suggests that the targeting of pallidum by striatum could involve a population code, a notion compatible with processing models for other levels of the motor system (Georgopoulos et al., 1986, 1989; Bizzi et al., 1991).

In the experiments described here and briefly elsewhere (Flaherty and Graybiel, 1992a,b), we explicitly tested this proposal by making small paired injections of distinguishable retrograde tracers in the GPe and GPi of squirrel monkeys. We also directly determined, with double tracer and immunohistochemical labeling, whether enkephalinergic neurons project only to GPe. Our findings demonstrate that distributed clusters of projection neurons project to small sites in GPe and GPi, and that, although individual clusters can project both to GPe and to GPi, the neurons within them project only to one of these targets. Matrisomal clustering thus seems to ensure that, for at least some matrisomes, the direct and indirect pathways of the basal ganglia can be targeted in parallel by sets of spatially distributed but locally coordinated populations of neurons.

\section{Materials and Methods}

In 36 hemispheres of 18 adult squirrel monkeys (Saimiri sciureus) we injected the retrograde tracers wheat germ agglutinin conjugated to horseradish peroxidase (WGA-HRP; $n=12$ ), wheat germ agglutinin conjugated to enzymatically inactivated apo-horseradish peroxidase and labeled with colloidal gold ( $\mathrm{HG} ; n=17$ ), the $\beta$-subunit of cholera toxin (CTB; $n=28)$, and Fluorogold $(n=6)$. Injections were made bilaterally, under stereotaxic guidance, into pairs of target sites in GPe $(n=24)$ and GPi $(n=30)$. The injection site coordinates for hemispheres in which both the GPe and the GPi injections were successful are listed in Table 1. In some of the hemispheres, injections into the substantia nigra $(n=7)$ were also made, and analyzed with respect to patterns of tyrosine hydroxylase immunostaining. The distributions of tracers transported to the striatum were compared to each other, and to the distribution of enkephalin-immunoreactive striatal neurons. Serial-section analysis, and also single-section analysis of dual staining patterns, was carried out.

Tracer injections. Neuroanatomical tracers were pressure-injected with a Picopump (World Precision Instruments) through glass micropipettes with internal tip diameters of 25-35 $\mu \mathrm{m}$, according to surgical protocols described previously (Flaherty and Graybiel, 1991). Briefly, monkeys were given a small dose of the analgesic buprenorphine $\mathrm{HCl}(0.01 \mathrm{mg} /$ $\mathrm{kg}$, s.c.) preoperatively, and then ancsthetized with ketamine $(30 \mathrm{mg}$ ) $\mathrm{kg}$, i.m.) and a single initial dose of sodium pentobarbital $(5 \mathrm{mg} / \mathrm{kg}$, i.p.). A few monkeys did not receive buprenorphine, but instead received a larger dose of sodium pentobarbital $(10 \mathrm{mg} / \mathrm{kg}$, i.p.). Anesthetic level was determined by monitoring heart rate with an ECG, respiration rate, muscle tone, and corneal and toe-pinch reflexes. Supplementary doses of ketamine $(10 \mathrm{mg} / \mathrm{kg}$, i.m.) were given as needed to maintain anesthesia. In the course of the surgeries, distinguishable anterograde tracers were also deposited in the cerebral cortex under electrophysiological guidance, for experiments reported separately (Flaherty and Graybiel,
Table 1. Retrograde tracer injection site pairs that labeled overlapping or interdigitating cell clusters in the putamen, and their stereotaxic coordinates

\begin{tabular}{|c|c|c|c|c|}
\hline Case & GPe & $\begin{array}{l}\text { Coord. } \\
\text { (AHL) }\end{array}$ & $\mathrm{GPi}$ & $\begin{array}{l}\text { Cord. } \\
\text { (AHL) }\end{array}$ \\
\hline
\end{tabular}

Overlap of labeled regions

\begin{tabular}{|c|c|c|c|c|}
\hline \multirow[t]{3}{*}{$34 \mathrm{R}$} & CTB & 11.0 & HG & 9.5 \\
\hline & & 14.0 & & 13.0 \\
\hline & & 6.5 & & 7.0 \\
\hline \multirow[t]{3}{*}{$35 \mathrm{~L}$} & СТВ & 10.5 & $\mathrm{HG}$ & 9.0 \\
\hline & & 13.0 & & 12.5 \\
\hline & & 7.0 & & 6.5 \\
\hline \multirow[t]{3}{*}{$34 \mathrm{~L}$} & СТВ & 11.0 & $\mathrm{HG}$ & 9.5 \\
\hline & & 14.0 & & 13.0 \\
\hline & & 7.0 & & 7.0 \\
\hline \multirow[t]{3}{*}{$39 \mathrm{R}$} & $\mathrm{HG}$ & 11.5 & СТВ & 10.0 \\
\hline & & 13.0 & & 12.5 \\
\hline & & 6.5 & & 6.0 \\
\hline \multirow[t]{3}{*}{$40 \mathrm{R}$} & $\mathrm{HG}$ & 10.0 & CTB & 9.5 \\
\hline & & 13.5 & & 11.5 \\
\hline & & 7.0 & & 6.0 \\
\hline \multirow[t]{3}{*}{$40 \mathrm{~L}$} & $\mathrm{HG}$ & 9.5 & СТВ & 9.5 \\
\hline & & 13.5 & & 11.5 \\
\hline & & 7.0 & & 6.0 \\
\hline
\end{tabular}

Interdigitation of labeled regions

$\begin{array}{rrrr}39 \mathrm{~L} H \mathrm{HG} & 11.0 & \text { CTB } & 10.0 \\ & 13.0 & & 12.5 \\ & 7.0 & & 4.5\end{array}$

A, anterior; $\mathbf{H}$, horizontal; L, lateral.

1991, 1993). CTB (Sigma, Inc.) was prepared as a saturated solution by adding $0.5 \mathrm{mg}$ of CTB to $20 \mu 1$ of sterile water, stirring vigorously, and letting the precipitate settle for $5 \mathrm{~min}$ before filling the injection pipette. Fluorogold ( $1 \%$ solution; Fluorochrome, Inc.) and WGA-HRP $(15 \%$ solution; Sigma) were dissolved in sterile saline. HG was prepared in advance according to the method of Basbaum and Menetrey (1987).

After $2 \mathrm{~d}$ survival times, during which buprenorphine $(0.01 \mathrm{mg} / \mathrm{kg}$, s.c.) was given twice daily, the monkeys were perfused under deep barbiturate anesthesia $(50 \mathrm{mg} / \mathrm{kg}$, i.p.). The brains were blocked, cryoprotected, and cut coronally at $40 \mu \mathrm{m}$ on a freezing microtome as described previously (Flaherty and Graybiel, 1991).

Histology. Adjacent sections were processed in series, or single sections were doubly stained, to compare the distributions of injected tracers, neurotransmitter-related compounds (enkephalin, tyrosine hydroxylase), and cell bodies (Nissl substance).

The location of WGA-HRP was demonstrated with the tetramethylbenzidine method of Mesulam (1978) with minor modifications (Flaherty and Graybiel, 1991, 1993). Fluorogold labeling was analyzed in sections processed for WGA-HKP, HG, or fluorescent immunostaining; it tended to be obscured in diaminobenzidine (DAB)-immunostained sections. Nissl substance was stained with cresylecht violet on mounted defatted slides.

HG was demonstrated by three to six $20 \mathrm{~min}$ incubations of loose sections in a $1: 1$ mixture of the initiator and enhancer solutions of the IntenSe BL silver enhancement kit (Amersham), alternated with brief washes in $0.1 \mathrm{M}$ phosphate buffer (PB). The silver-enhanced tissue was fixed with a 5 min incubation in $2.5 \%$ sodium thiosulfate in PB, mounted, dehydrated, and coverslipped. The mounting medium Eukitt was found to cause rapid fading of $\mathrm{HG}$ staining, but sections coverslipped in Permount (Fisher) did not fade delectably in up to 2 years. Many sections containing $\mathrm{HG}$ injection sites or regions of retrograde $\mathrm{HG}$ transport were processed with diaminobenzidine for immunoperoxidase staining, or with tetramethylbenzidine for WGA-HRP staining. There was no sign of cross-reaction between $\mathrm{HG}$ and any peroxidase stain.

Enkephalin, CTB, and tyrosine hydroxylase were demonstrated immunohistochemically. Enkephalin staining was relatively sensitive to 


\begin{tabular}{|c|c|c|c|c|}
\hline $\begin{array}{l}\text { First } \\
\text { label }\end{array}$ & $\begin{array}{l}\text { Second } \\
\text { label }\end{array}$ & $\begin{array}{l}\text { Neurons } \\
\text { counted }\end{array}$ & $\begin{array}{l}\text { Hemi- } \\
\text { spheres }\end{array}$ & $\begin{array}{l}\% \text { Doubly } \\
\text { labeled }\end{array}$ \\
\hline GPe & GPi & 4812 & 5 & $2.1 \pm 2.7$ \\
\hline GPe & Enk & 3602 & 3 & $71.3 \pm 7.6$ \\
\hline GPi & Enk & 4799 & 4 & $10.0 \pm 3.6$ \\
\hline
\end{tabular}

Neurons were counted only in regions of the putamen in which neurons of the two typcs were extensively intermingled. In the first and second rows, doubly labeled neurons are expressed as the percentage of the total number of GPe-labeled neurons; in the third row, they are expressed as the percentage of GPi-labeled neurons. Both strongly and weakly double-labeled cells were counted.

endogenous peroxidase activity and detergent levels; consequently, we stored tissue in $0.1 \%$ sodium azide in $\mathrm{PB}$, pretreated it for $5 \mathrm{~min}$ in $10 \%$ methanol and $3 \%$ hydrogen peroxide in $\mathrm{PB}$, and exposed it to $0.3 \%$ Triton X-100 in PB in only one 5 min incubation before beginning the immunostaining. Sections were incubated with polyclonal antiserum against CTB (List Biolabs; 1:2000 dilution), enkephalin (Incstar; antimet-enkephalin; 1:1000 dilution), or tyrosine hydroxylase (Eugene Tech; $1: 1000$ ) for $2 \mathrm{~d}$. Sections to be singly stained were then incubated with a biotinylated secondary antibody, stained with the DAB-avidin-biotin peroxidase technique (Vector), mounted, dehydrated, and coverslipped. Striosomes were identified as striatal regions in which neurons expressed low enkephalin-like immunorcactivity (Graybicl and Chcssclct, 1984). The borders of GPe were determined by enkephalin staining (Haber and Elde, 1982). The substantia nigra pars compacta (SNc) was delimited from the $\mathrm{SNr}$ by its greater tyrosine hydroxylase staining.

For sections first immunostained and then stained for $\mathrm{HG}$, bound antibody was labeled with a secondary antibody conjugated to the fluorochrome CY3 (Jackson Immunoresearch), mounted, and coverslipped in $90 \%$ glycerol $/ 10 \% \mathrm{~PB}$ with $5 \mathrm{mg} / \mathrm{ml} \mathrm{DABCO}(1,4$-diazabicyclo-[2,2,2]-octane; Aldrich) added to retard fading. Fluorescence lasted at least 6 weeks without appreciable fading. HG was also compatible with $D A B$ peroxidase immunohistochemistry, except that in cells darkly stained with $D A B$ it was sometimes difficult to determine whether $H G$ granules were present.

Quantitative analysis. Neurons in singly stained nonfluorescent sections were counted in the putamen at $250 \times$ with a Leitz Ortholux microscope coupled to a Cohu CCD video camera and a computerized image analyzer (Biocom, Les Ulis, France). Counts were made within multiple sample squares $3.8 \times 10^{4} \mu \mathrm{m}^{2}$ in area and $40 \mu \mathrm{m}$ in thickness. Sample squares were placed in the regions with the highest density of labeled neurons. Nissl-stained neurons were counted in the same hemispheres in similar regions of the putamen. An average of 173 retrograde neurons or 406 Nissl-stained neurons were counted per slide. Small Nissl-stained cells with dark nuclei (diameters of $7 \mu \mathrm{m}$ or less) were considered to be glia and were not counted. In determining cell counts per $\mathrm{mm}^{3}$, the relative shrinkage of tissue processed with different techniques was assessed by comparing the total area of the putamen on each slide. Cell counts were then multiplied by the appropriate shrinkage correction factors.

Doubly stained fluorescent sections were examined with a laser scanning confocal imaging system (Bio-Rad MRC 600) coupled to a Zeiss Axioplan microscope. The laser confocal system had two photodetector channels, permitting simultaneous analysis of the fluorescent label in the same or in depth-summed optical planes. CY3 fluorescence was viewed with a YHS filter block; HG granules were examined with either transmitted or reflected light. Digitized images of the separate channels were stored and merged to produce pseudocolor composites.

Doubly labeled cells were counted by systematically scanning sections through the putamen at a magnification of $400 \times$, at which the field displayed on the Bio-Rad screen was approximately $300 \mu \mathrm{m}$ in diameter. Sections analyzed were approximately $1 \mathrm{~mm}$ apart and spanned the rostrocaudal extent of the retrograde labeling in the striatum. Within a given section through the putamen, all and only the $300 \mu \mathrm{m}$ fields that contained more than one cell of each type were analyzed. On the average, this was true for about 20 fields per slide. This protocol was necessary in order to avoid diluting the percentage of doubly labeled cells by counting singly labeled cells in regions where only one projection was labeled. Thus, counts were made only for cases with injection sites in regions of GPe and GPi that were topographically related in terms of their striatopallidal inputs. Neurons were counted only in the putamen because most of the injection sites were in regions of the pallidum that receive inputs from the putamen rather than from the caudate nucleus. The numbers of neurons counted are listed in Table 2.

Injection site reconstructions and overlay drawings of labeled projections were made with a Wild stereomicroscope equipped with a drawing tube, as previously described (Flaherty and Graybiel, 1991, 1993). The center of the injection site was considered to be the region in which the tracer completely obliterated cytoarchitecture; the injection site halo contained distinct labeled cells and heightened background staining. To estimate injection site volume, the coronal area through the center of each injection site was measured with the Biocom computerized image analyzer, and the effective radius of the injection site was calculated from that area. The injection site volume was then estimated as the volume of the equivalent sphere. The relative shrinkage of tissue processed with different histological techniques was taken into account with shrinkage factors as described above.

\section{Results}

Characteristics of the injection sites

In 18 monkeys, there were 63 successful injections of the differentiable retrograde tracers CTB, IIG, WGA-HRP, and Fluorogold in GPe, GPi, and the SN. The deposits were not randomly distributed in the target nuclei, but were aimed at regions in which injections produced retrograde labeling in the midlateral and lateral putamen. Compared to WGA-HRP, CTB and HG deposits formed small, well-defined injection sites with much less tracer deposition along the pipette track, and were more effective than WGA-HRP for labeling a single segment of the pallidum without contamination of the other segment. Fluorogold injections more often produced lesions at the sites of injection than did CTB, HG, and WGA-HRP injections. Most analysis, therefore, was carried out with $C T B$ and $H G$.

Of the 45 CTB or $\mathrm{HG}$ injection sites, 31 were confined entirely to their target nucleus, as opposed to 2 of the 12 WGA-HRP injection sites. Injection site diameters averaged $1.1 \mathrm{~mm}$ for 20 $\mathrm{nl} \mathrm{CTB,} 0.4 \mathrm{~mm}$ for $90 \mathrm{nl} \mathrm{HG}, 2.3 \mathrm{~mm}$ for $10 \mathrm{nl}$ WGA-HRP, and $0.4 \mathrm{~mm}$ for $10 \mathrm{nl}$ Fluorogold. HG had a tendency (but much less so than WGA-HRP) to label the bottom part of the pipette track, forming elongated injection sites. Consequently HG was a more successful tracer when used for GPe injections; if used in GPi injections, the track tended to contaminate GPe. In a few hemispheres the GPe injection site contaminated the putamen to some extent. Label transported within the putamen from such contamination was readily distinguishable from label transported from the pallidum, and was restricted to a few hundred microns around the injection site.

\section{Striatal neurons projecting to GPe and GPi are organized in matrisomal clusters}

In all cases of $\mathrm{HG}, \mathrm{CTB}$, and WGA-HRP injection into the pallidum, with injection sites ranging from about 0.1 to $3.0 \mathrm{~mm}$ in cross-sectional diameter, the predominant pattern of labeling in the putamen was of neurons aggregated into clusters and bands (Fig. 1). Scattered labeled neurons also appeared outside the clusters. The cell clusters labeled with WGA-HRP or CTB were especially conspicuous because of the tendency of these tracers to label neuropil as well as cell bodies, but even $\mathrm{HG}$, which did not label neuropil, labeled distinct cell clusters. By contrast, Fluorogold injections in the pallidum produced a sparse, apparently uniform distribution of labeled striatal neurons, lacking pronounced clusters. To determine whether this difference in labeling was due to different qualities in the transport of Fluorogold or to the relative faintness of fluorescent labeling, we also analyzed sections in which CTB had been demonstrated 

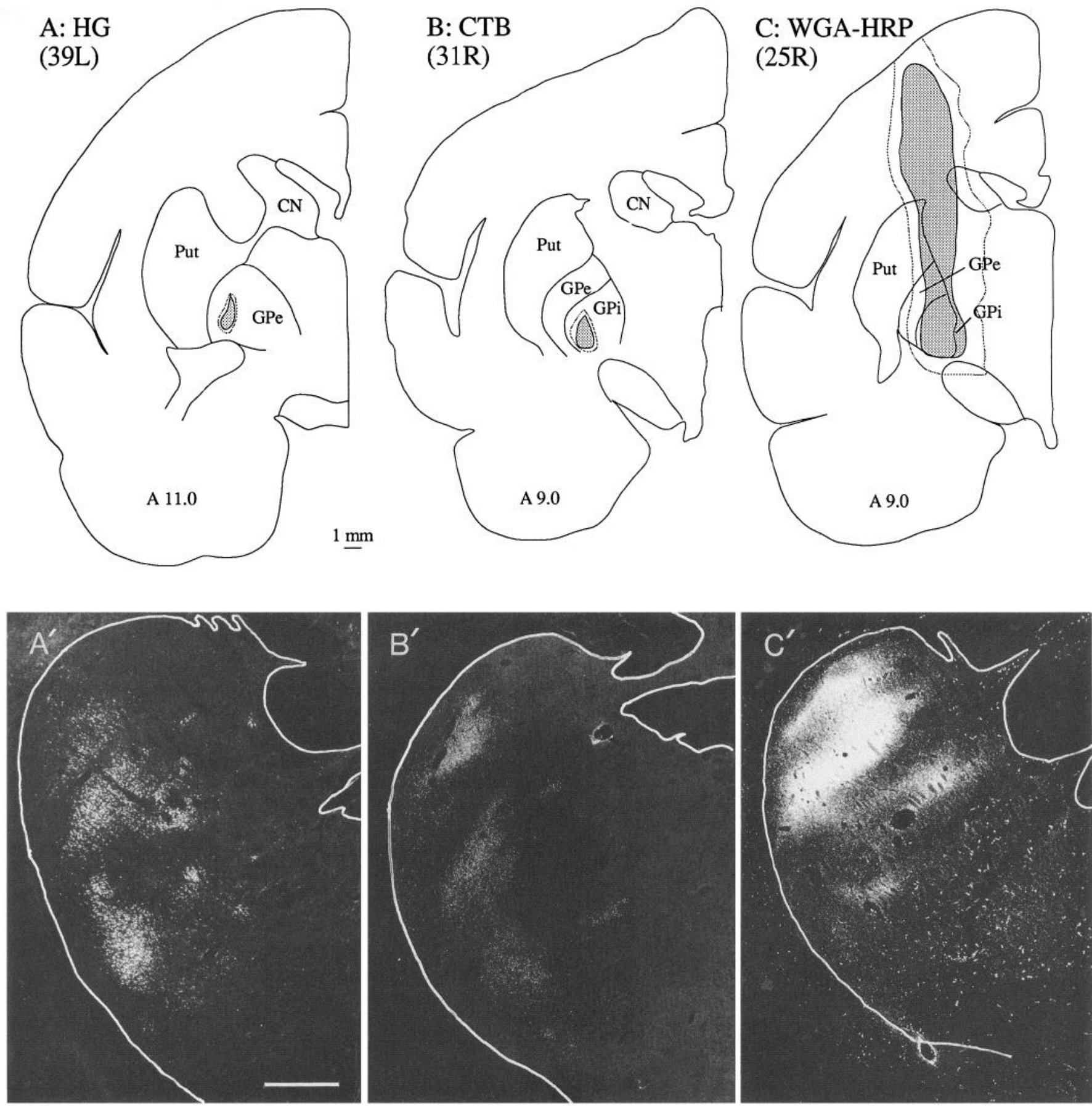

Figure 1.-Clustered pattern of retrograde neuronal labeling in the putamen following tracer injections in GPe and GPi. $A-C$, Typical retrograde tracer injection sites in the pallidum of three hemispheres, showing the much smaller injection sites that can be made with HG and CTB than with WGA-HRP. Broken lines represent the diffusely labeled halos surrounding the densely labeled injection sites. $A^{\prime}-C^{\prime}$, Dark-field photographs of the corresponding patterns of retrograde labeling in the putamen of each hemisphere. Note that retrogradely labeled neurons lie in clusters regardless of the tracer used. $A$ and $A^{\prime}$ (hemisphere $39 L$ ), HG injection site in GPe at stereotaxic level A 11.0, and labeling in the putamen at level A 12.5 . $B$ and $B^{\prime}$ (hemisphere $31 R$ ), CTB injection site in GPi at level A 9.0, and labeling in the putamen at A 12.5 . $C$ and $C^{\prime}$ (hemisphere $25 R$ ), WGAHRP injection site and typical contaminated pipette track filling much of GPi, and labeling in the putamen at A 12.0. Borders of the putamen are outlined on the photographs. $B, B^{\prime}, C$, and $C^{\prime}$ have been printed left-right reversed for ease of comparison. $C N$, candate nucleus; Put, putamen. Scale bar (in $A$ ), $1 \mathrm{~mm}$ for $A^{\prime}-C^{\prime}$.

Figure 2. Tracer sites and three-dimensional reconstructions of labeled striatal output cell clusters. $A$ and $A^{\prime}$ (hemisphere $39 L$ ), An HG injection site in GPe, and retrograde labeling traced in cross sections through the putamen. Sections were spaced at $320 \mu \mathrm{m}$ intervals and the drawings were superposed in sets of three. Note that the labeled cell clusters were not completely confluent at any level of the putamen. $B$ and $B^{\prime}$ (hemisphere $28 R$ ), A larger CTB injection site in GPi, and retrogradely labeled cell clusters in the putamen. Sections were spaced at $120 \mu \mathrm{m}$ intervals and superposed in sets of three. A confluent "main field" of labeled cells appears at levels A 7.0 to A 8.5. Because the labeling in $B^{\prime}$ ' was drawn at more frequent intervals than that in $A^{\prime}$, more levels through the putamen are shown. However, the total anteroposterior extent of labeling in the putamen label was similar (about $6 \mathrm{~mm}$ ) in the two cases. 


\section{Injection Sites}

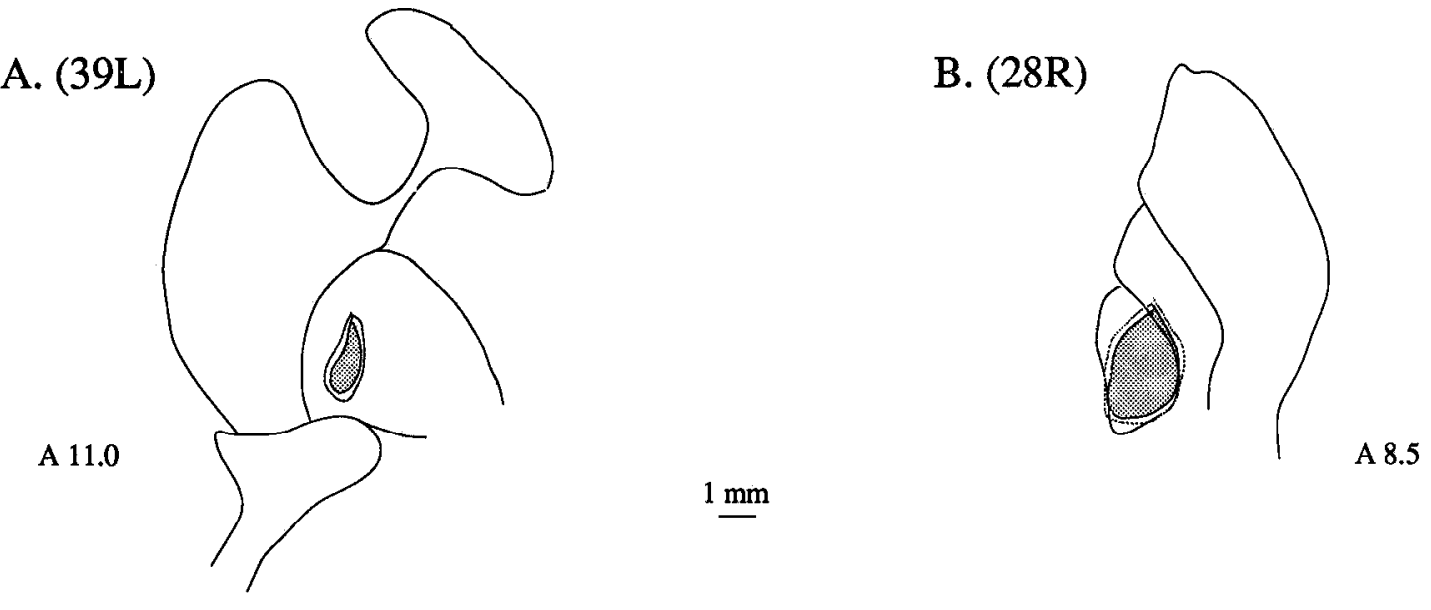

$\mathrm{A}^{\prime}$. Putamen projections (39L)
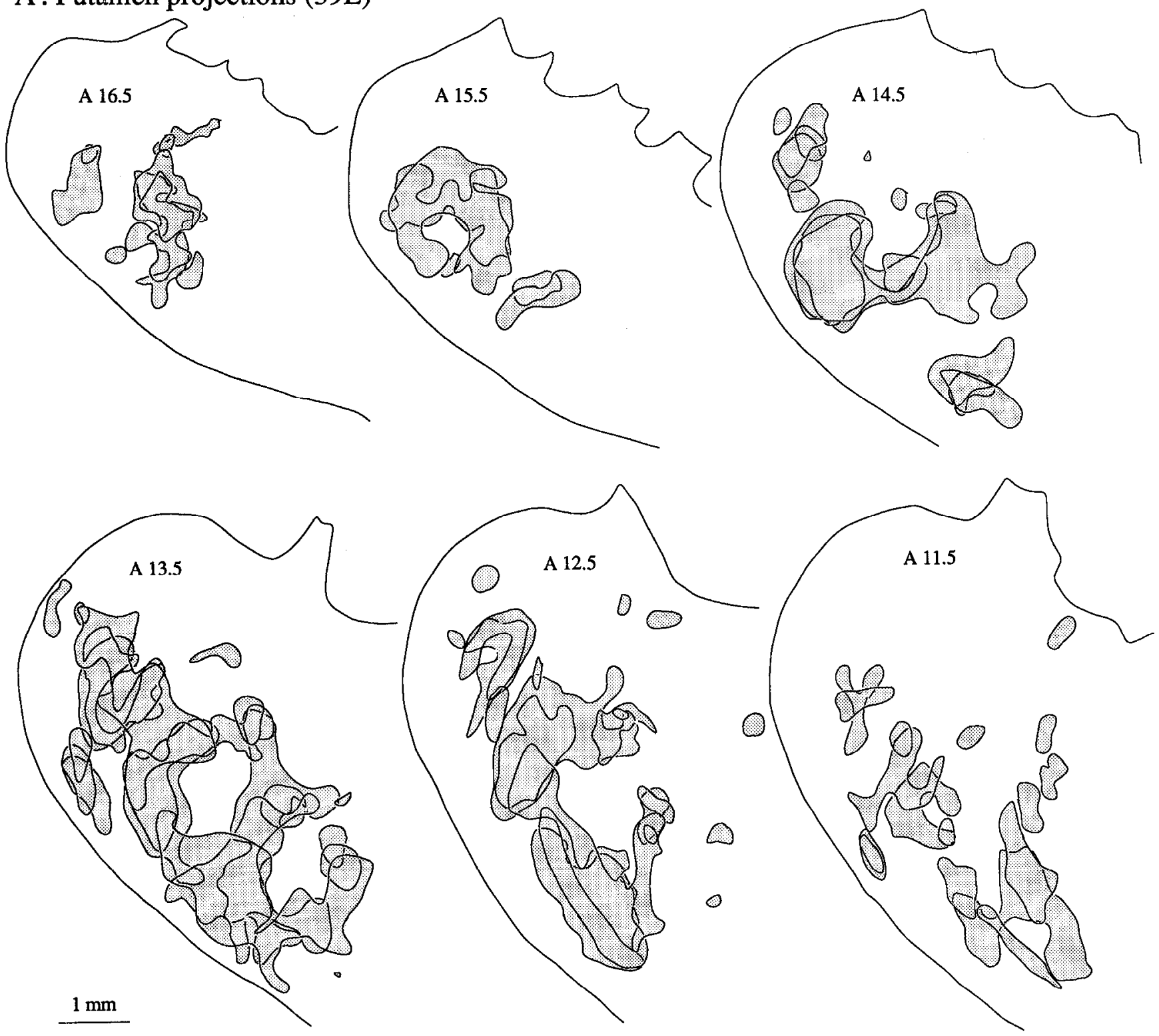


\section{B'. Putamen projections (28R)}

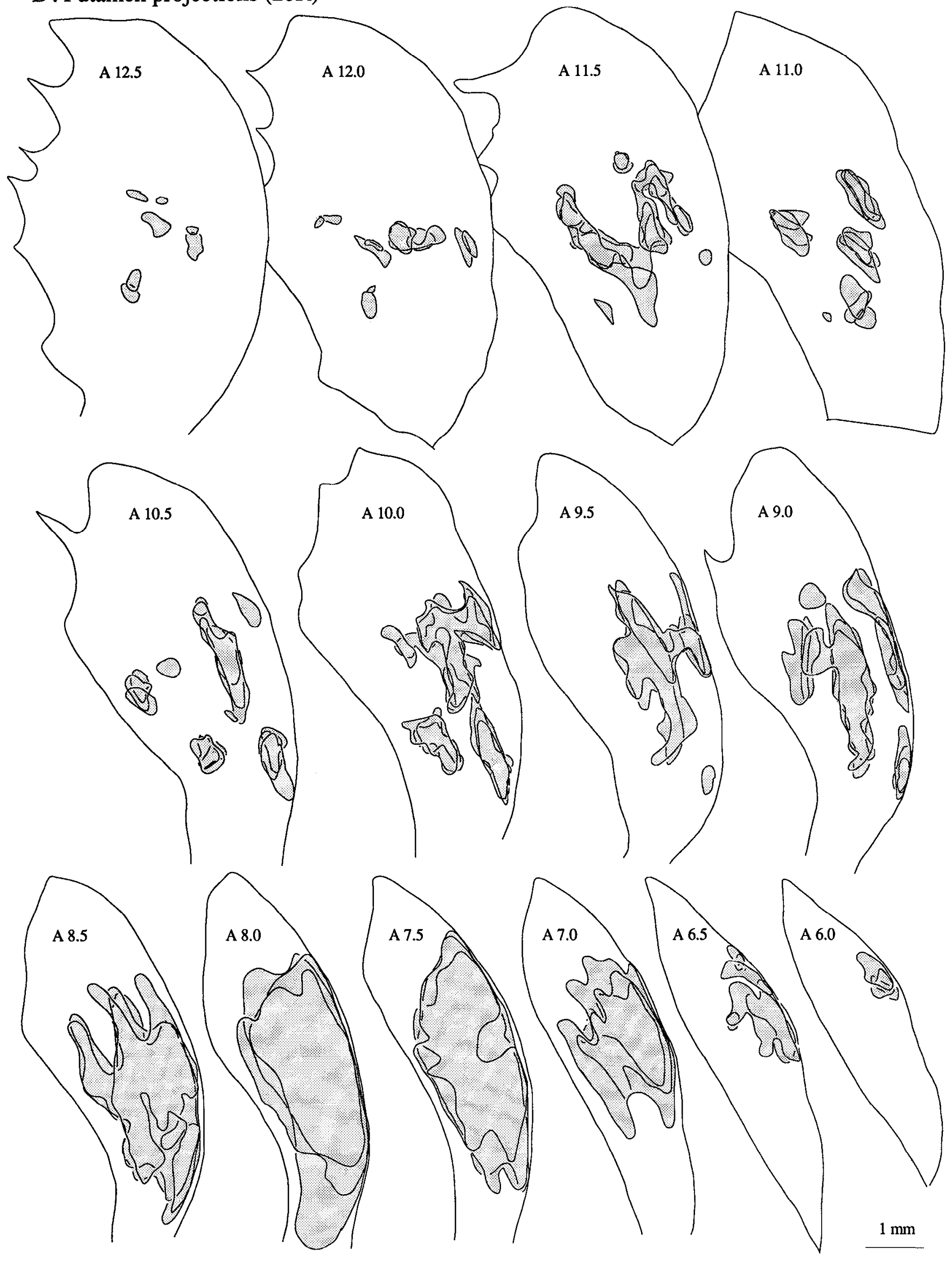




\section{A. Injection site (40L)}
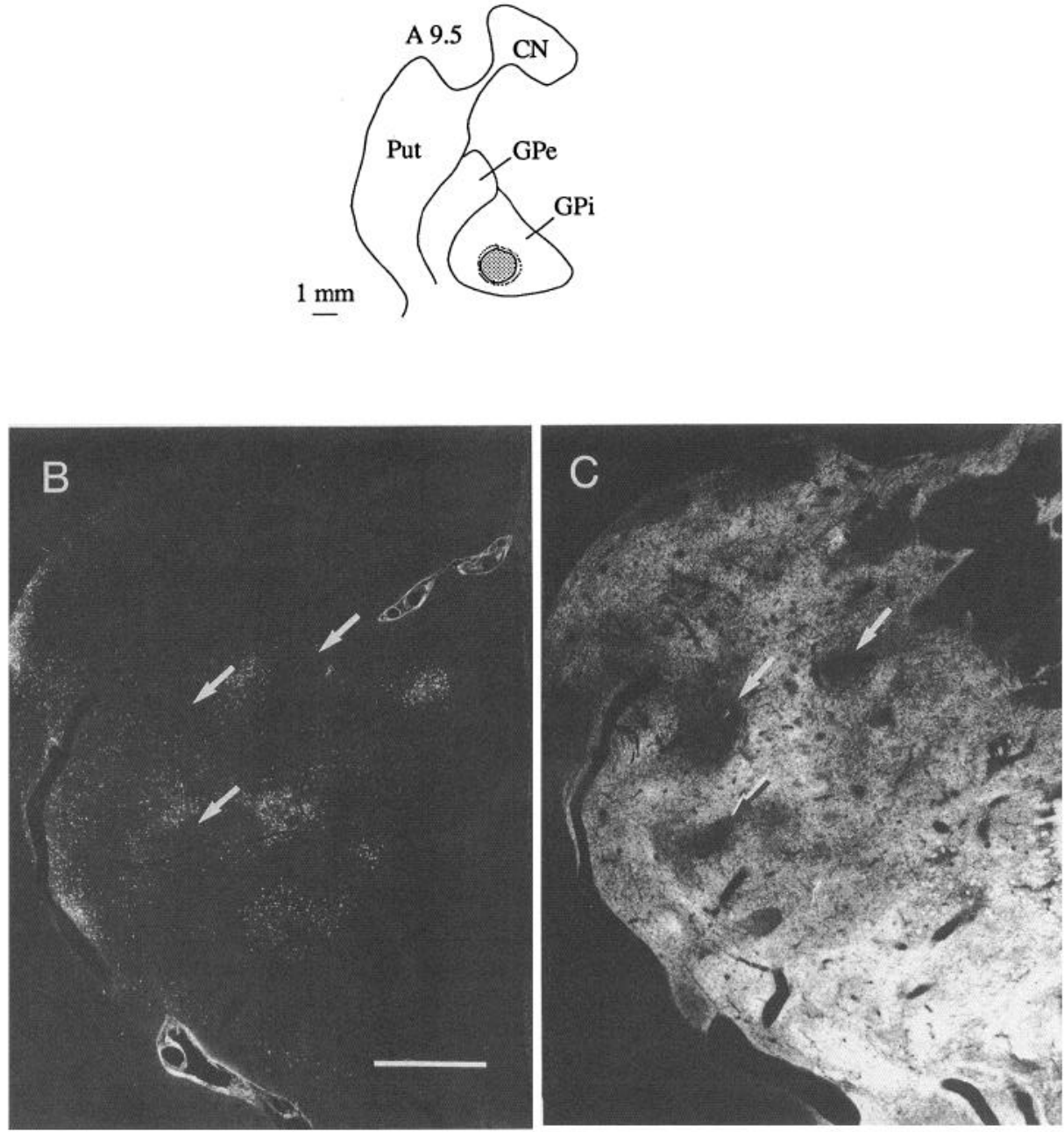

Figure 3. Pallidal output cells form discrete clusters in the striatal matrix (hemisphere 40L). A, CTB injection site in GPi at stereotaxic level A 9.5. B, Reverse-contrast photograph of CTBlabeled cells in the putamen at level A 12.0. $C$, Reverse-contrast photograph of a tissue section, serial to that in $B$, immunostained for enkephalin to demonstrate striosomes (dark zones). Striosomes are marked with arrows in $C$, and the corresponding regions are also marked in $B$. Comparison of $B$ and $C$ indicates that the clusters of labeled neurons in $B$ are in the matrix, and thus are matrisomes. Scale bar in $B, 1 \mathrm{~mm}$ for $B$ and $C$. either by a secondary antibody conjugated to the fluorochrome CY3, or by a fluorochrome ABC method with a Texas redconjugated avidin-biotin complex. Such sections showed the same patchy cell distribution seen in DAB-stained CTB sections, indicating that it was not simply a property of fluorescent labeling of neurons that made it difficult to see cell clusters retrogradely labeled with Fluorogold.

The labeled cell clusters ranged in size from about 0.1 to 1 $\mathrm{mm}$ in diameter, and those labeled from GPe and GPi were not obviously distinguishable in shape, size, number, or distribution. The clusters were, on average, somewhat smaller and more discrete than those seen previously in studies based on large WGA-HRP injection sites not completely contained in a single pallidal segment (Giménez-Amaya and Graybiel, 1990, 1991). The retrograde labeling in the putamen elicited by an approximately $1-\mathrm{mm}$-diameter injection in GPe or GPi extended, in total distribution, approximately $6 \mathrm{~mm}$ anteroposteriorly, $3 \mathrm{~mm}$ dorsoventrally, and $2 \mathrm{~mm}$ mediolaterally. In cross section, the clusters often had a long axis that ran obliquely from the dorsomedial to the ventrocaudal putamen, an orientation also seen in afferent-fiber clusters labeled by cortical inputs (Flaherty and Graybiel, 1991, 1993).

When reconstructed in three dimensions, the retrogradely labeled fields in the putamen formed branching lattices in which individual zones were often, but not always, connected by thin necks (Fig. 2). Large pallidal injection sites produced striatal labeling in which some of the labeled zones fused, producing a "main field" of relatively homogeneous labeling surrounded by more discrete cell clusters (see Fig. $2 B^{\prime}$ and Giménez-Amaya and Graybiel, 1990). However, hemispheres with small injection sites often did not have a homogeneous main field (Fig. $2 A^{\prime}$ ), and even in hemispheres with large injection sites, most sections through the striatum contained two to five labeled cell clusters, separated by up to $1 \mathrm{~mm}$ or more of unlabeled or sparsely labeled tissue.

Comparisons of tracer distributions and met-enkephalin immunostaining for striosomes demonstrated that the cell clusters labeled by either GPe or GPi injections were in the striatal matrix (Fig. 3). Striosomes were not, however, entirely free of labeled cells, confirming patterns observed with larger injections not confined to a single segment of the pallidum (GiménezAmaya and Graybiel, 1990, 1991).

In seven hemispheres the $\mathrm{SN}$ was injected with a retrograde tracer. In all cases the injection site included both $\mathrm{SNr}$ and $\mathrm{SNc}$, as judged by tyrosine hydroxylase immunostaining of adjacent sections. Fluorogold was injected in three of the cases, and it produced sparse, diffuse cell labeling in the striatum similar to that produced when Fluorogold was injected into the pallidum. 


\section{A. Injection sites (42L)}

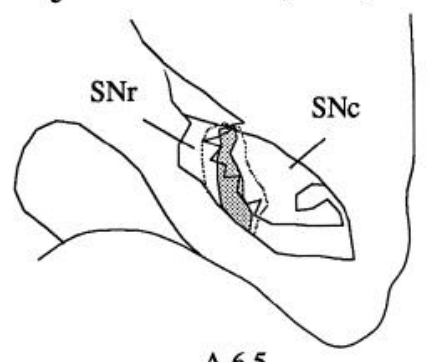

A 6.5
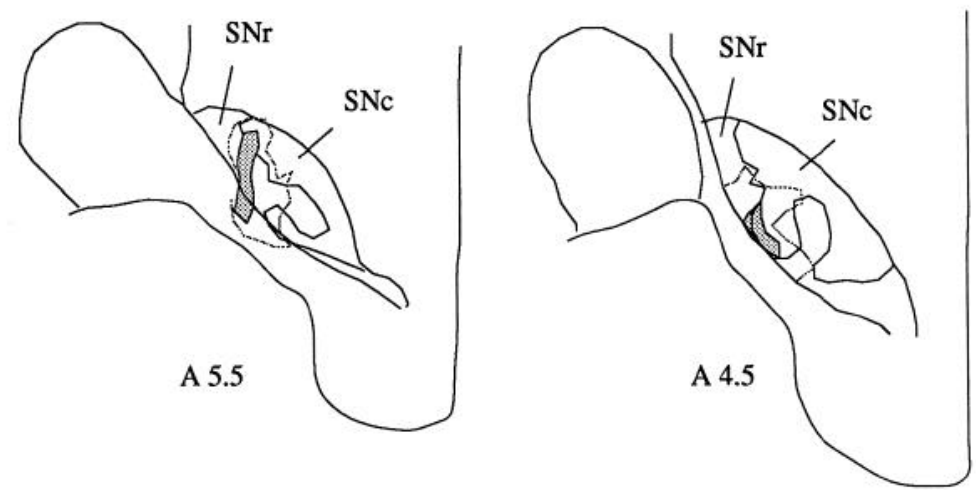

$1 \mathrm{~mm}$
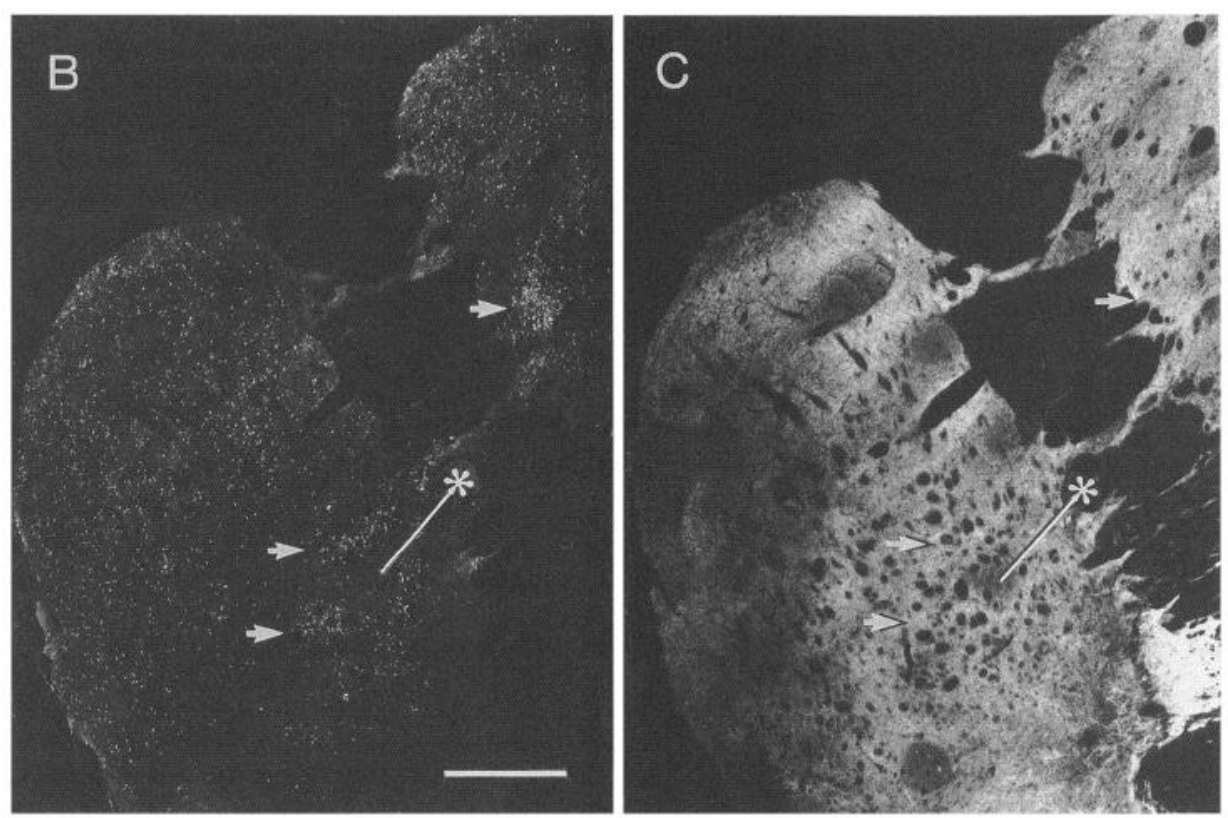

Figure 4. Striatal labeling from tracer injections in the SN. A, An injection site, produced by three confluent injections of CTB, that extended into both SNc and SNr over several millimeters (hemisphere 42L). Broken lines represent the diffusely labeled halos surrounding the densely labeled injection site. $B$, Reverse-contrast photograph of CTB-labeled neurons in the putamen and caudate nucleus at stereotaxic level A 12.5. Much of the labeling is diffuse, but occasional cell clusters are present. They are marked with arrows in $B$, and the corresponding sites are also marked with arrows in $C$, a section serial to that in $B$, immunostained for enkephalin to demonstrate striosomes (dark zones). One striosome is marked with an asterisk in $C$, and the corresponding region in $B$ is similarly marked. Comparison of $B$ and $C$ indicates that the clusters of labeled neurons in $B$ are in the matrix and thus are matrisomes (see matched fiducial arrows and asterisks). Scale bar in $B, 1 \mathrm{~mm}$ for $B$ and $C$.

In the other four hemispheres, we made multiple, confluent injections of CTB. These large nigral injection sites produced cell labeling in the matrix of the putamen that was notably less patchy and covered more of the striatum than that labeled by the small pallidal injection sites (Fig. 4). In each hemisphere, however, some regions of the striatum contained discrete patches of labeled cells, and some of the SN-labeled cell clusters were in the matrix.

\section{Individual matrisomes contain intermingled GPe-projecting and GPi-projecting neurons}

Four lines of evidence suggested that clusters of striatal neurons projecting to GPe are not strictly segregated from those projecting to GPi.

Cell counting. Within the bounds of the clusters, labeled neurons were always interspersed with unlabeled neurons, suggesting that only some of the neurons in a cluster projected to a given target site. To estimate this number, in six hemispheres we compared cell counts of all Nissl-stained neurons per $\mathrm{mm}^{3}$ with the counts of retrogradely labeled neurons per $\mathrm{mm}^{3}$ in the most densely labeled regions of the output matrisomes (Fig. $5 A$ ). The maximum cell counts of labeled output neurons, 24,000 \pm 6500 cells $/ \mathrm{mm}^{3}$ (mean $\pm \mathrm{SD}$ ) for GPe-labeled matrisomes and $24,700 \pm 3800$ cells $/ \mathrm{mm}^{3}$ for GPi-labeled matrisomes, were less than $38 \%$ of the total neuronal count, $65,500 \pm 8000$ cells/ $\mathrm{mm}^{3}$ ( $p<0.0001$ for both comparisons). The counts of GPeand GPi-labeled neurons did not significantly differ from each other.

Because the small CTB and HG injection sites in GP did not fill all of one pallidal segment, it was possible that the unlabeled neurons projected to other, uninjected regions of the same segment. We therefore also counted neurons labeled in four hemispheres by large WGA-HRP injection sites. These sites filled much of one pallidal segment and, on average, had volumes 10- 

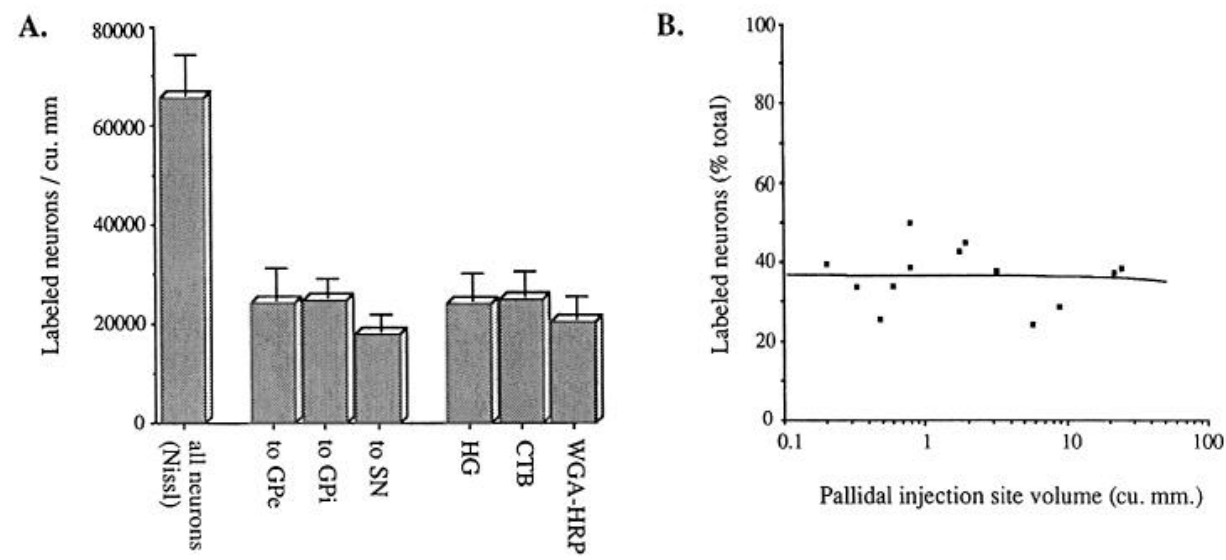

Figure 5. Evidence that striatal neurons projecting to a particular target nucleus make up only a fraction of the neurons in individual matrisomes. $A$, After injections into $\mathrm{GPe}, \mathrm{GPi}$, or $\mathrm{SN}$, the maximum number of retrogradely labeled striatal neurons in the most densely labeled matrisomal regions is less than half of the total neuronal count observed in corresponding zones in Nissl-stained sections. Bars to right show averages for each tracer type following injections into the pallidum, demonstrating that the cell counts obtained were independent of the tracer used. Error bars indicate $1 \mathrm{SD} . B$, The percentage of retrogradely labeled striatal neurons in the most densely labeled matrisomal regions, plotted against injection site volumes within the pallidum for 13 cases. Retrogradely labeled neurons never exceeded $50 \%$ of the total over a 75 -fold range of injection site volumes. Note that the $y$-axis is logarithmic.

20 times greater than the volumes of the HG or CTB injections. The maximum density of neurons in the putamen labeled by the large pallidal WGA-HRP injections was $20,400 \pm 4500$ cells $/ \mathrm{mm}^{3}$ ( $31 \%$ of the number of the total neuronal count). Thus, the maximum density of retrogradely labeled striatal neurons was not significantly dependent on the injection site size over a 75 -fold range (Fig. $5 B$ ), or on the tracer used (Fig. $5 A$ ). We did not examine the relationship between the total number of labeled neurons and injection site size. After nigral injections, even in the densest zones of retrograde labeling, only 17,900 \pm 3400 cells $/ \mathrm{mm}^{3}$, or $27 \%$ of the total neuronal count, were labeled in the caudate nucleus.

Serial-section analysis. GPe and GPi were injected with pairs of retrograde tracers in 16 hemispheres. In seven of them, the retrogradely labeled matrisomes were in the same general region of the putamen for at least some anteroposterior levels. In all but one of these seven hemispheres, the labeled clusters in the putamen contained both neurons projecting to GPe and neurons projecting to GPi (Fig. 6). The spatial relationship between the labeled GPe projections and GPi projections in the doubly labeled cases did not seem to be governed by a single rule: the two sets of matrisomes neither perfectly overlapped nor systematically avoided each other. Significantly, in the regions of intersection of the two fields of labeled projection neurons, the retrogradely labeled cell clusters were not constrained to avoid each other. As a rough measure of the anatomical relationship between the sites in GPe and GPi that can receive projections from the same regions of the putamen, we averaged the stereotaxic coordinates of the four pairs of injection sites that elicited the most extensive overlap of GPe-labeled and GPi-labeled matrisomes (Table 1, the first 4 entries). The result suggests that an injection in GPi that is approximately $1.5 \mathrm{~mm}$ posterior, 0.8 $\mathrm{mm}$ ventral, and $0.2 \mathrm{~mm}$ medial to its companion injection in GPe will retrogradely label cell clusters that at least partially overlap those labeled by the GPe injection.

For three injection sites of these overlapping pairs, there was a small amount of contamination of GPe by the GPi injection site, raising the possibility that this contamination contributed to or caused the overlapping matrisomes. However, the radial topography of the striatopallidal fibers suggests that the transport from the inadvertently injected regions of $\mathrm{GPe}$ - which bordered on $\mathrm{GPi}$ - would label regions of the striatum medial and caudal to the regions labeled by the GPe injection proper. Moreover, overlapping of matrisomes labeled by the two tracers were also seen in the three hemispheres in which each injection site was completely confined to a single pallidal segment.

In a single hemisphere of the seven with retrograde label in the same general region of the striatum, labeled cell clusters projecting to GPe and GPi were segregated from each other and never overlapped (Fig. 7). The cell clusters did not share common borders, however, and appeared to be randomly distributed with respect to one another. The pair of pallidal injection sites in this hemisphere did not have the same stereotaxic relationship as those pairs that labeled overlapping matrisomes, the most obvious difference being a greater mediolateral separation.

Single-section analysis: double retrograde labeling. The results of the serial-section comparisons just described support the claim that in single matrisomes the neurons projecting to GPe are interspersed with neurons projecting to GPi. As an independent check of this conclusion, we processed single sections with both the silver enhancement reaction to demonstrate $\mathrm{HG}$ and fluorescence immunostaining for CTB in five hemispheres $(34 \mathrm{~L}$, $34 \mathrm{R}, 35 \mathrm{~L}, 39 \mathrm{R}$, and $40 \mathrm{R}$ ) in which labeled striatal neurons projecting to GPe and GPi were intermingled. Confocal microscopic analysis demonstrated that when neurons retrogradely labeled with the two tracers appeared in the same general region of the striatum, they were often and sometimes extensively intermingled (Fig. 8A).

Single-section analysis: retrograde label and enkephalin immunostaining. Sections from four hemispheres (34L, 34R, 35L, and $41 \mathrm{~L}$ ) were doubly stained to show neurons retrogradely labeled from HG injections in GPi and neurons immunostained for met-enkephalin. Enkephalin immunostaining, although a less direct method for identifying GPe-projecting neurons than retrograde labeling, preferentially labeled neurons projecting to $\mathrm{GPe}$ (see below) and had the advantage of labeling many neurons throughout the matrix rather than the small subset of neurons labeled by small pallidal injection sites. Comparisons between 


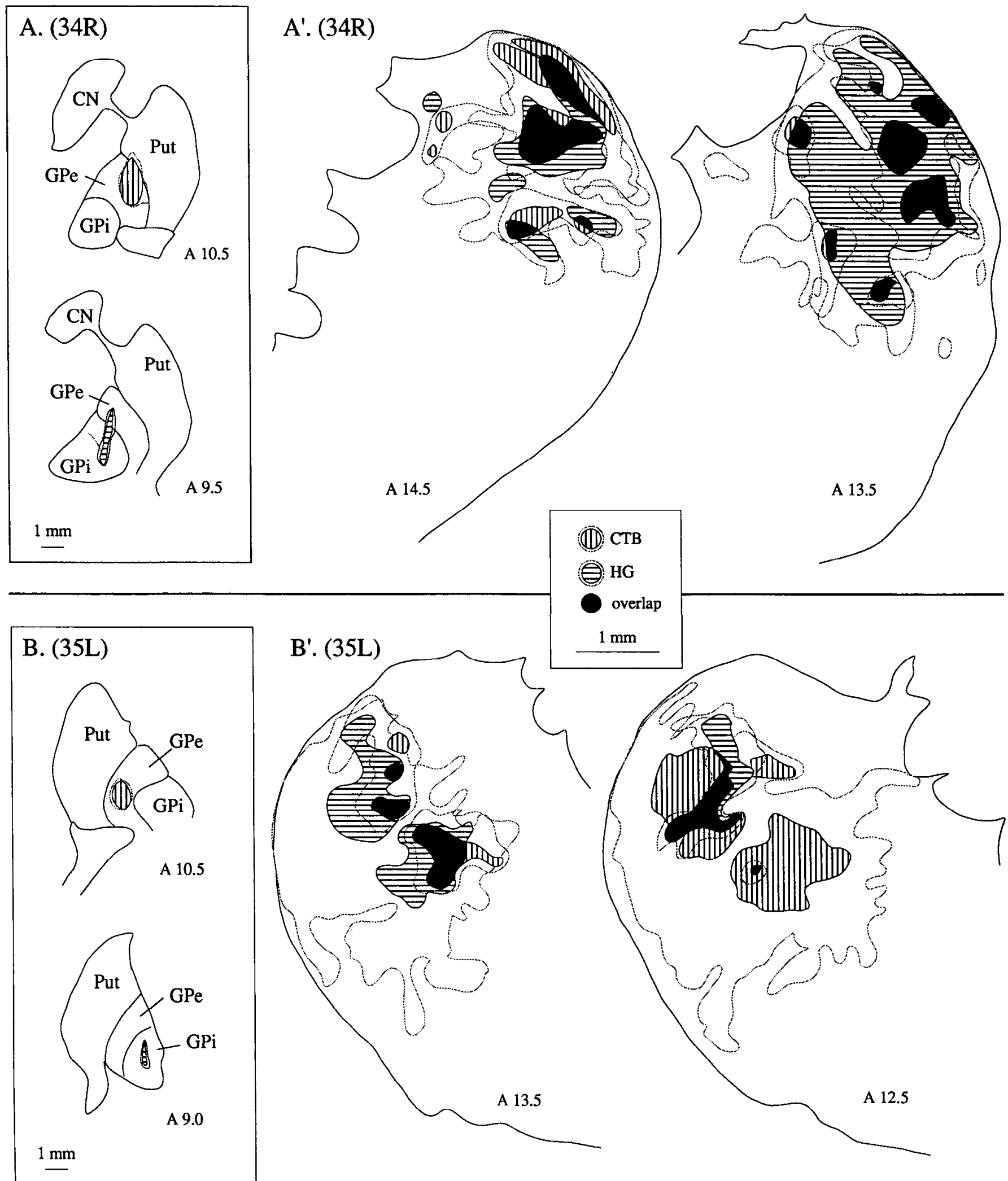

Figure 6. Evidence that matrisomes projecting to GPe can overlap matrisomes projecting to GPi. $A$ and $B$, Paired HG (in GPe) and CTB (in GPi) retrograde tracer injection sites in hemisphere $34 R\left(A\right.$ and $\left.A^{\prime}\right)$ and hemisphere $35 L$ ( $B$ and $\left.B^{\prime}\right) . A^{\prime}$ and $B^{\prime}$, Overlay drawings of regions containing retrogradely labeled cells in coronal sections through the putamen of the two hemispheres. Stereotaxic coordinates are noted for each drawing. Hatched regions represent the zones of dense labeling for the two tracers: horizontal hatching, HG; vertical hatching, CTB. Surrounding broken lines represent the lightly labeled halos. Black represents regions of overlap of the zones of dense labeling. 


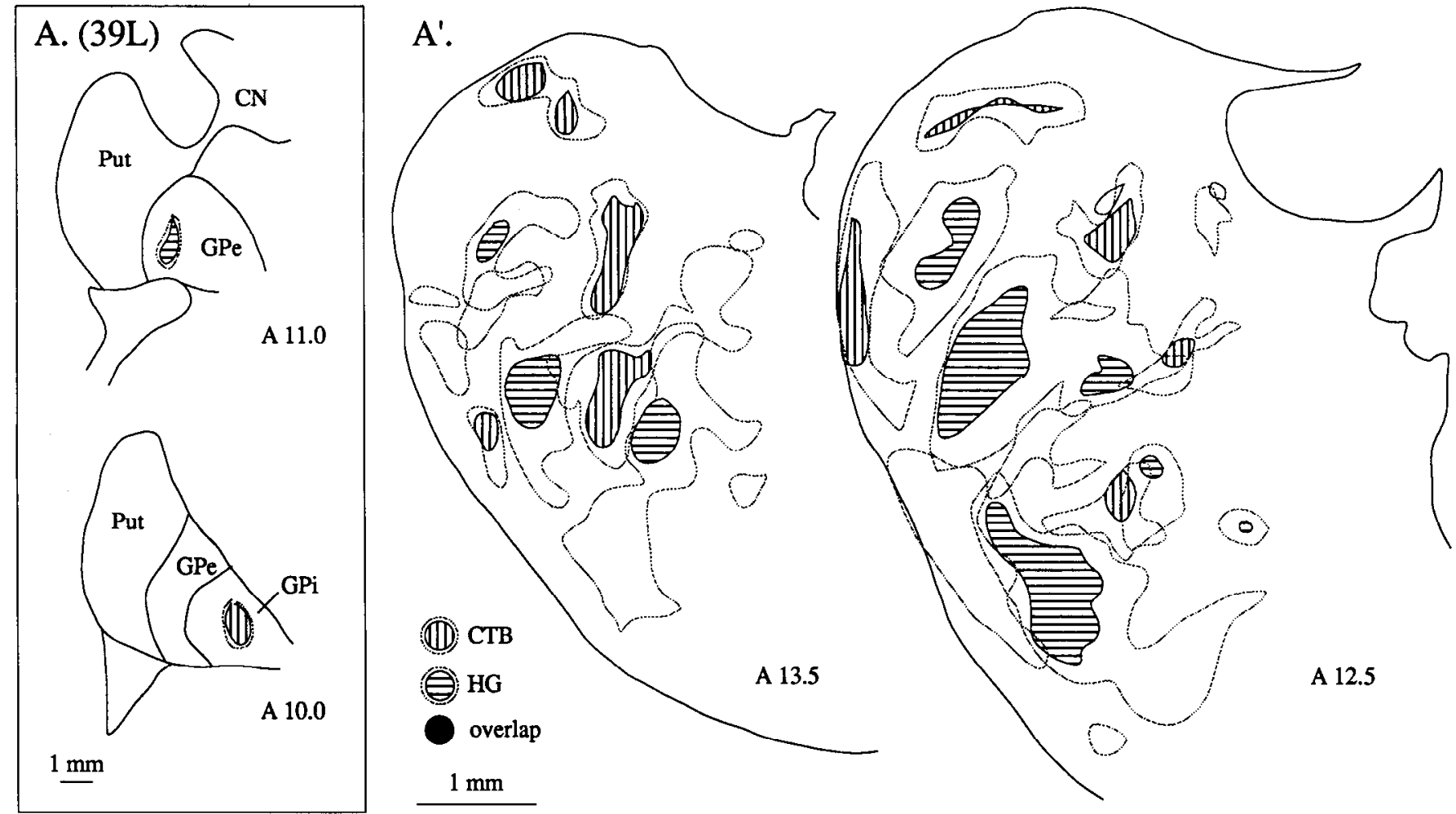

Figure 7. Interdigitation of matrisomes projecting to GPe and GPi (hemisphere $39 L$ ). $A$, Paired HG (in GPe) and CTB (in GPi) retrograde tracer injection sites. $A^{\prime}$, Overlay drawings containing regions of retrogradely labeled cells in coronal sections through the putamen. Hatched regions represent the dense zones of labeling for the two tracers: Horizontal hatching, HG; vertical hatching, CTB. Surrounding outlines represent the lightly labeled halos. One of the HG sections drawn (horizontal hatching, level A 12.5) is also shown in the photograph of Figure 1 $A^{\prime}$.

the distributions of GPi-labeled neurons and enkephalin-positive neurons could thus be made throughout the striatum. Such comparisons showed that clusters of GPi-labeled neurons always contained intermingled enkephalin-positive neurons.

\section{Individual neurons in the putamen project either to GPe or to $G P i$}

Few neurons are retrogradely double labeled from both GPe and $G P i$. The confocal microscopic analysis of doubly retrogradely labeled sections described above also allowed us to determine whether single neurons contained both tracers. As an index of how many striatal neurons sent axon collaterals to both GPe and GPi, we counted doubly labeled neurons in the five hemispheres with single-section double staining for GPe and GPi labeling. Labeled striatal neurons were counted only in regions where neurons labeled with the two tracers were closely intermixed, specifically, when both types of neurons appeared in a microscope field approximately $300 \mu \mathrm{m}$ in diameter. All of the fields counted were in the putamen.

Even in the regions of closely intermixed GPe-labeled and
GPi-labeled neurons, very few neurons were doubly labeled (Fig. $8 B$, Table 2). Expressed as a percentage of the counted GPelabeled neurons, there were $2.1 \pm 2.7 \%$ (mean $\pm \mathrm{SD}$ ) doubly labeled neurons, a mean that did not significantly differ from zero. Re-expressing the numbers of doubly labeled neurons as a percentage of the total of GPi-labeled neurons $(1.3 \pm 1.7 \%$ and $3.3 \pm 4.9 \%$, respectively) did not yield means significantly different from zero. Two of the five hemispheres (35L, 40R) had GPi injection sites that were predominantly in the medial division of GPi, but these had about the same percentage of doubly labeled neurons as did the three other cases in which the GPi injection sites were predominantly in the lateral division of GPi.

Labeling of enkephalin-positive neurons by tracer injections in GPe or GPi. As a second index of the degree to which GPe and GPi receive separate projections from the striatum, we combined, in single sections, fluorescence immunohistochemistry for met-enkephalin with silver enhancement to demonstrate $\mathrm{HG}$ (Fig. 8C,D; Table 2). This technique was applied to tissue from three hemispheres with HG injections in GPe (39L, 39R, and

Figure 8. Laser confocal microscope views of double retrograde labeling in the putamen following retrograde tracer injections in GPe and GPi. $A$ and $B$, GPe-projecting and GPi-projecting striatal neurons are intermingled but few individual neurons project to both segments. Neurons projecting to GPe $(r e d)$ were labeled with a fluorescent antibody to CTB; those projecting to GPi (green) were labeled with HG. $A$, Low-power view showing the extensive intermingling of GPe- and GPi-projecting neurons (hemisphere $34 R$ ). $B$, Higher-power view showing that cells contain one or the other label but rarely both (hemisphere $35 L$ ). Arrow points to the single double-labeled cell in this section. $C$ and $D$, Striatal neurons projecting to GPi rarely express enkephalin; those projecting to GPe commonly do. In $C$, GPi-projecting neurons are green and enkephalincontaining neurons are red (hemisphere $41 L$ ). Neurons in this field contain only one or the other label. In $D$. GPe-projecting neurons are green and enkephalin-containing neurons are red (hemisphere $39 L$ ). Doubly labeled neurons are common, and are indicated with arrows. Scale bars, $50 \mu \mathrm{m}$. 


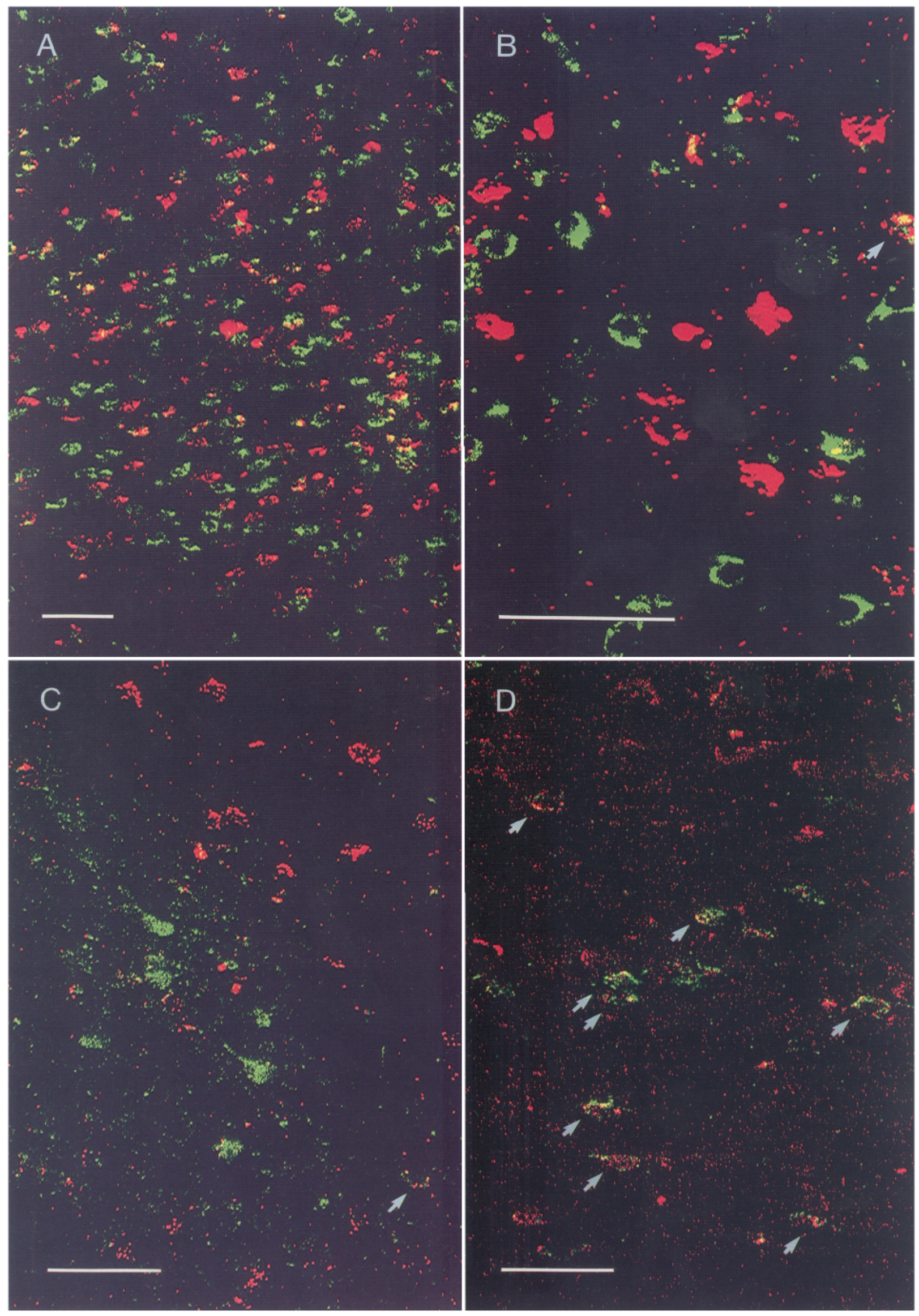


$41 \mathrm{R})$ and to four with $\mathrm{HG}$ injections in GPi (34L, 34R, 35L, and $41 \mathrm{~L}$ ). Only $10.0 \pm 3.6 \%$ of the labeled GPi-projecting neurons were enkephalin positive $(2.8 \pm 1.6 \%$ strongly positive and $7.2 \pm 4.4 \%$ weakly positive). By contrast, $71.3 \pm 7.6 \%$ of the labeled GPe-projecting neurons were enkephalin positive (41.1 $\pm 0.1 \%$ strongly positive and $30.1 \pm 7.3 \%$ weakly positive) The difference in frequency of enkephalin-positive GPe-labeled neurons and enkephalin-positive GPi-labeled neurons was highly significant $(p<0.000001)$.

One of the four hemispheres (35L) with GPi-labeled cells had an injection site that was predominantly in the medial division of GPi. That hemisphere had a slightly higher percentage of enkephalin-positive GPi-labeled neurons than the other three hemispheres, which had injection sites in the lateral division of GPi ( $14.7 \%$ vs $6.6 \%, 8.7 \%$, and $9.4 \%$ for the other three). However, the increase in that hemisphere was not in doubly labeled cells that were strongly enkephalin positive. Only the number of weakly enkephalin-positive doubly labeled cells increased.

\section{Discussion}

These experiments demonstrate four characteristics of the output organization of the primate striatum. First, even retrograde tracer injection sites that are very small, and that are completely contained in a single segment of the GP, label multiple clusters of neurons in the matrix compartment of the putamen. Second, these matrix cell clusters (matrisomes) contain both neurons projecting to GPc and ncurons projecting to GPi. Third, individual neurons within these clusters project only to one or the other pallidal segment. Fourth, neurons projecting to GPe and GPi can also be distinguished on the basis of their enkephalin immunostaining. Thus, channeling of outputs from the striatal matrix to the two segments of the pallidum occurs at the neuronal level, but the larger-scale matrisome level of organization does not directly reffect this separation by target nucleus. We propose, instead, that one function of matrisomal clustering may be to coordinate striatal output signals sent into the direct (GPi) and indirect (GPe) pathways of the basal ganglia. Because these pathways have-to a furst approximation-respectively, disinhibitory and inhibitory effects on the cerebral cortex, their coordination may be important for the normal control of movement.

\section{Retrograde tracers: technical considerations}

The novel combination of the tracers CTB and HG allowed a clear demonstration of compartmental organization as well as single-section double labeling of striatopallidal neurons. These tracers, in fact, delimited the modular output organization of the matrix more cleanly than WGA-HRP has (Giménez-Amaya and Graybiel, 1990, 1991), probably because of the smaller injection sites obtained with them. It is interesting, however, that $\mathrm{HG}$ and CTB injection sites an order of magnitude smaller in volume than our typical WGA-HRP injection sites did not produce labeling that was an order of magnitude more patchy, nor were the patches an order of magnitude smaller. The combination of CTB and $\mathrm{HG}$ also permitted injection sites to be made small enough that closely adjacent regions, such as GPe and GPi, could be injected without cross-contamination.

Our finding of projection neuron clustering with all three nonfluorescent tracers strongly argues that the compartmentalization is truly a feature of the striatopallidal projection. Fluoro- gold - in contrast to these three nonfluorescent tracers-did not effectively show the compartmentalized retrograde distribution. Previous studies in which this and other fluorescent retrograde tracers have been injected into striatal targets have also failed to demonstrate retrogradely labeled cell clusters in the striatum as clearly as those using WGA-HRP (Feger and Crossman, 1984; Beckstead and Cruz, 1986; Parent et al., 1989; Giménez-Amaya and Graybiel, 1990; Selemon and Goldman-Rakic, 1990). This difference raised the question of whether the compartmentalization could be an artifact of WGA-HRP labeling. Our results with CTB and HG provide evidence that it is not. Fluorogold may label a sparse projection system, or Fluorogold-labeled matrisomes may be difficult to see because of the faintness of Fluorogold labeling compared to the much stronger HG, CTB, and WGA-HRP labeling. The faintness was not, however, due to fluorescence labeling per se: when CTB was labeled with a fluorescent rather than peroxidase-labeled antibody, its distribution was still obviously patchy.

\section{Striosome-matrix segregation}

Previous comparisons of striosomes with clusters of neurons retrogradely labeled by large tracer deposits in GP have shown that the labeled clusters are predominantly, if not exclusively, in the matrix (Giménez-Amaya and Graybiel, 1990, 1991). However, these previous findings also indicated that labeled neurons were not completely absent from striosomes. We were curious whether smaller injections would produce cell labeling that was perfectly confined to the matrix. They did not. Even very small injections labcled scattered neurons in striosomes. These apparent exceptions are similar to other examples of striosome/matrix compartmentalization in the striatum; for instance, afferent fibers from the somatosensory and motor cortex that are predominantly restricted to clusters in the matrix nonetheless weakly innervate striosomes (Flaherty and Graybiel, 1991, 1993). It would be useful to know whether these minor innervations allow interaction between striosome and matrix processing, or represent systematic separations of the two (Gerfen et al., 1990; Ragsdale and Graybiel, 1990), or are developmental aberrations.

\section{Output architecture of the matrix}

These experiments strongly support the view that the matrix compartment of the putamen contains clusters of output neurons projecting to the two segments of the GP. The small number of cascs with injections in the SN pointed to some clustering of striatonigral matrix neurons as well (see below). Our experiments do not, however, establish the matrix-neuron clusters as striatal modules in the same sense that striosomes are. In contrast to the demonstration of striosomes by many different neurochemical markers, no neurochemical markers have yet been shown to delimit matrisomes. In fact, our demonstration that enkephalin-immunoreactive and GPi-projecting neurons are intermixed in individual matrisomes (see below) helps to account for why there are not enkephalin-positive and enkephalin-negative patches in the matrix. However, there are inhomogeneities in enkephalin immunostaining there (T. Aosaki, M. Kimura, and A. M. Graybiel, unpublished observations), and there are other detectable neurochemical heterogeneities in the matrix as well, at least in the primate striatum (Graybiel and Ragsdale, 1978; Nastuk and Graybiel, 1985; Joyce et al., 1986; Graybiel et al., 1987; Hirsch et al., 1989; Holt et al., 1992).

The fact that output cell clusters are labeled in the putamen 
by tracer injections in either GPe or GPi made it natural to propose that different clusters project to these two different target nuclei (Divac, 1984; Feger and Crossman, 1984; JiménezCastellanos and Graybiel, 1989; Selemon and Goldman-Rakic, 1990; Giménez-Amaya and Graybiel, 1991). Our findings, however, argue against this being the general rule.

First, our dual-tracer experiments directly demonstrated that GPe-projecting and GPi-projecting neurons can intermingle in individual matrisomes. This finding suggests that any given matrisome in the putamen projects to a pair of regions, one in GPe and the other in GPi. In anesthetized animals we could not identify the somatotopic relation of the pairs of injection sites by recording from the pallidum. However, when the injection sites in the two pallidal segments labeled projection neurons in approximately the same region of the putamen, the relationship between the injection sites, as expressed in stereotaxic coordinates, fit remarkably well with the radial organization of striatopallidal projections (Feger and Crossman, 1984; Parent et al., 1989; Selemon and Goldman-Rakic, 1990; Giménez-Amaya and Graybiel, 1991).

Second, we found that enkephalin-positive neurons were much more likely to project to GPe than to GPi, and that GPi-labeled neurons were intermixed with enkephalin-positive neurons. This evidence was important confirmation of the dual-tracer data, for the enkephalin immunostaining was independent of tracer injection locus. Our evidence does not prove that all striatopallidal matrisomes have a mixture of neurons projecting to the two segments, but such mixing appears to be, at minimum, common.

Third, even in the densest parts of matrisomes labeled from GPe or GPi, an average of only about $38 \%$ of the neurons were labeled. This was true over a 75 -fold range of injection site sizes, even though with the larger injections there were increases in the total numbers of labeled neurons and their distributions across the striatum. The percentage of retrogradely labeled neurons we found after pallidal injections is similar to percentages reported for the rat (Bolam et al., 1981; Loopuijt and van der Kooy, 1985).

Because matrix neurons also project to the $\mathrm{SN}$, we compared, in a limited number of cases, the distributions of striatal neurons projecting to GP with those projecting to SN. In the two hemispheres in which the same striatal territory was labeled by $\mathrm{HG}$ injections in GP and by CTB injections in $\mathrm{SN}$, there was some intermixing of neurons projecting to the two regions. The SNlabeled matrix neurons were more sparsely and widely distributed in the matrix than were those labeled by the pallidal injections, but the cases were not directly comparable because of the much larger size of the SN injection sites. Clusters of striatal neurons projecting to $\mathrm{SNr}$ have been reported for the cat (Desban et al., 1989; Jiménez-Castellanos and Graybiel, 1989), and a single injection in $\mathrm{SNr}$ in the monkey has been reported to label retrogradely discrete zones in the putamen that are similar in appearance to those following our pallidal injections (Selemon and Goldman-Rakic, 1990). The SN injections labeled a maximum of $27 \%$ of the neurons per output patch. This value is lower than the $50-70 \%$ reported for the rat's caudoputamen (Bolam et al., 1981; Loopuijt and van der Kooy, 1985). This difference may reflect the apparently much higher percentage of striatal neurons in the rat that send branching projections to multiple target nuclei (see below). The SN injections tended to label striosomal cell clusters, as expected from previous experiments (Gerfen, 1985; Jiménez-Castellanos and Graybiel, 1989).
Separation of GPe-directed and GPi-directed pathways through the putamen at the level of single neurons

As detected by retrograde double labeling, the percentage of neurons projecting to both segments of the pallidum did not significantly differ from zero. Previous retrograde double-labeling studies have given widely varying percentages of striatal neurons that project to more than one target nucleus. Part of the inconsistency can be attributed to species differences: studies in rats with a variety of techniques (Bolam et al., 1981; Loopuijt and van der Kooy, 1985; Kawaguchi et al., 1990) have generally indicated a much higher degree of collateralization between the GPe and GPi/SNr pathways than those in cats or monkeys (Feger and Crossman, 1984; Beckstead and Cruz, 1986; Parent et al., 1989; Giménez-Amaya and Graybiel, 1990; Selemon and Goldman-Rakic, 1990).

The finding that enkephalin-like immunoreactivity is predominantly a feature of neurons projecting to GPe provides independent evidence that GPe-projecting and GPi-projecting neurons are separate populations, and also serves as a control for the possibility that the tracer findings were due to potential dual-tracer artifacts. The values we found for expression of enkephalin, $71 \%$ by GPe-labeled neurons and $10 \%$ for GPi-labeled neurons, are consistent with those in other species (Penny et al., 1986; Gerfen and Young, 1988; Besson et al., 1990; Gerfen et al., 1990).

Clearly; however, expression of enkephalin-like immunoreactivity was not an infallible indicator of neurons projecting to GPe for the $10 \%$ of the GPi-projecting neurons that were enkephalin positive. This group of neurons may also project to $\mathrm{GPe}$, but our double-retrograde labeling result, that only $2 \%$ of neurons project to both GPe and GPi, does not favor this possibility. In fact, only about $3 \%$ of the GPi-labeled neurons showed strong enkephalin immunostaining, a percentage closer to the $2 \%$ retrogradely double-labeled neurons we saw. Conceivably, then, the GPi-labeled neurons that strongly express enkephalin also project to GPe. An alternate possibility is that they project to the medial division of GPi, which has relatively high levels of enkephalin compared to the lateral division of GPi (Haber and Elde, 1982). Our data showed a slight increase in the amount of enkephalin-GPi double labeling when the injection site was in the medial division of GPi. This increase was predominantly in cells that weakly expressed enkephalin, however, rather than in those that showed strong enkephalin expression.

\section{Why have matrisomes?}

Our findings suggest that the clustering of output neurons into matrisomes is not simply a mechanism to channel particular types of striatal information to separate striatal target nuclei. What, then, is the function of this output organization? The contrast that we found between the single-cell and cell-cluster levels of organization of the striatal projection neurons suggests one possible answer. At the single-cell level, striatal neurons that project to GPe and GPi form separate classes. They can thus integrate inputs separately, process them according to their distinctive transmitter and receptor phenotypes, and influence GPe and GPi neurons in correspondingly distinct ways. Yet at the population level, neurons of the two types could have their activities coordinated by virtue of their commingling in matrisomes. Projection neurons in the striatum, including the striatum of primates (DiFiglia et al., 1976; Yelnik et al., 1991), are known to have extensive local axonal arbors of about the same 
Partial overlap

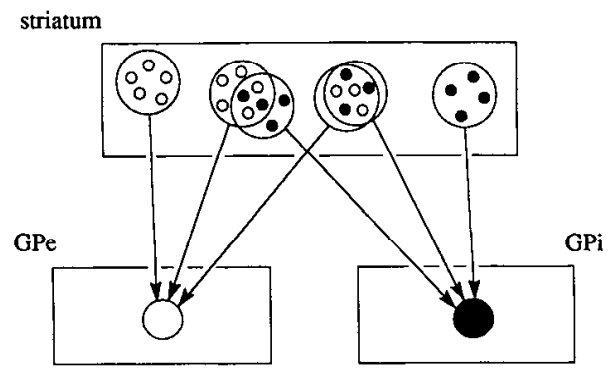

Paired matrisomes

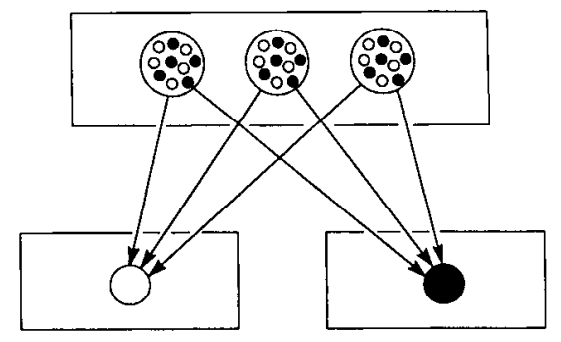

Figure 9. Two possible relations of GPe-projecting and GPi-projecting matrisomes. Matrisomes projecting to GPe and GPi may partially overlap (left) or completely overlap (right). Complete overlap, in which sets of matrisomes that converge on an injected site in $\mathrm{GPe}$ also converge on an injected site in $\mathrm{GPi}$, may depend on injecting functionally homologous sites in the two pallidal segments. dimensions as their dendritic trees (ca. $400 \mu \mathrm{m}$ diameter). By virtue of the clustering of projection neurons shown here, the projection neurons themselves, as well as interneurons and extrinsic afferents, could coordinately influence the activity of the neurons in any one matrisome.

This arrangement of clustered but individually distinct GPeprojecting and GPi-projecting striatal neurons would be a highly advantageous one for a network sending matched, coherent signals to the two pallidal segments. By having GPe-projecting and GPi-projecting striatal neurons clumped together in matrisomes, local regions of GPe and GPi receiving input from a given matrisome could be signaled in parallel. We suggest that, at least for some sets of matrisomes, such parallel signaling occurs for the sensorimotor putamen (Fig. 9). In the present experiments we could not make tracer injections in perfectly paired GPe and GPi sites, and so we could not rule out the possibility that the sets of GPe-projecting and GPi-projecting neurons are always only partially overlapped. However, experiments on physiologically identified cortical inputs to GPe- and GPi-projecting matrisomes strongly support the hypothesis that homologous, functionally matched regions of the two pallidal segments may receive inputs from complctcly overlapping sets of matrisomes (Flaherty and Graybiel, 1992a).

We also found that outputs from multiple clusters of striatal neurons spaced at considerable distances from each other can reach the same small region of either GPe or GPi. This remarkable pattern of striatopallidal convergence suggests another advantage of the matrisomal design: localized pallidal sites in each segment may collect inputs from multiple matrisomes, each of which could have different nearest-neighbor relations with adjoining striatal cell populations. The striatopallidal processing occurring as a result of this arrangement could therefore involve multiple integrations at the borders of different striatal matrisomes before convergence of these integrated signals onto local territories within the pallidum. Regional differences and neurochemical gradient variations through individual fields of matrisomal labeling could also be integrated at such local pallidal sites.

This analysis suggests a model of striatopallidal connectivity in which distributed sets of locally coherent striatal signals converge onto parallel sets of target sites in GPe and GPi (Fig. 9). These target structures have opposing, or at least complementary, influences on movement production, and they are themselves interconnected such that their activities should be closely interrelated (Hazrati et al., 1990; Kincaid et al., 1990; Smith and Bolam, 1990). Temporal as well as spatial coordination of signals sent from striatum to pallidum would be consistent with the matrisomal model outlined here.

\section{References}

Albin RL, Young AB, Penney JB (1989) The functional anatomy of basal ganglia disorders. Trends Neurosci 12:366-375.

Alexander GE, Crutcher MD (1990) Functional architecture of basal ganglia circuits: neural substrates of parallel processing. Trends Neurosci 13:266-272.

Ariano MA, Stromski CJ, Smyk-Randall EM, Sibley DR (1992) $\mathrm{D}_{2}$ dopamine receptor localization on striatonigral neurons. Neurosci Lett 144:215-220.

Basbaum AI, Menetrey D (1987) WGA-apoHRP gold: a new retrograde tracer for light- and electron-microscopic single- and doublelabel studies. J Comp Neurol 261:306-318.

Beckstead RM, Cruz CJ (1986) Striatal axons to the globus pallidus, entopeduncular nucleus and substantia nigra come mainly from separate cell populations in cat. Neuroscience 19:147-158.

Berretta S, Robertson HA, Graybiel AM (1992) Dopamine and glutamate agonists stimulate neuron-specific transcriptional activation of $c$-fos in the striatum. J Neurophysiol 68:767-777.

Besson M-J, Graybiel AM, Quinn B (1990) Coexpression of neuropeptides in the cat's striatum: an immunohistochemical study of substance $P$, dynorphin B and enkephalin. Neuroscience 39:33-58.

Bizzi E, Mussa-Ivaldi A, Giszter S (1991) Computations underlying the execution of movement: a biological perspective. Science 253: 287-291.

Bolam JP, Powell JF, Totterdell S, Smith AD (1981) The proportion of neurons in the rat neostriatum that project to the substantia nigra demonstrated using horscradish peroxidase conjugated with wheatgerm agglutinin. Brain Res 220:339-343.

Crossman AR (1987) Primate models of dyskinesia: the experimental approach to the study of basal ganglia-related involuntary movement disorders. Neuroscience 21:1-40.

Desban M, Gauchy C, Kemel ML, Besson MJ, Glowinski J (1989) Three-dimensional organization of the striosomal compartment and patchy distribution of striatonigral projections in the matrix of the cat caudate nucleus. Neuroscience 29:551-566.

DiFiglia M, Pasik P, Pasik T (1976) A golgi study of neuronal types in the neostriatum of monkeys. Brain Res 114:245-256.

Divac I (1984) The neostriatum viewed orthogonally. In: Ciba Foundation symposium, Functions of the basal ganglia, pp 201-215. London: Pitman.

Feger J, Crossman AR (1984) Identification of different subpopulations of neostriatal neurons projecting to globus pallidus or substantia nigra in the monkey: a retrograde fluorescence double-labelling study. Neurosci Lett 49:7-12.

Flaherty AW, Graybiel AM (1991) Corticostriatal transformations in the primate somatosensory systcm. Projections from physiologically mapped body-part representations. J Neurophysiol 66:1249-1263.

Flaherty AW, Graybiel AM (1992a) Input-output modularity of motor and somatosensory processing in the primate basal ganglia. Soc Neurosci Abstr 18:309.

Flaherty AW, Graybiel AM (1992b) Multiple stages of sensorimotor processing in the primate basal ganglia. IBAGS Abstr.

Flaherty AW, Graybiel AM (1993) Two input systems for body representation in the primate striatal matrix: experimental evidence in the squirrel monkey. J Neurosci 13:1120-1137. 
Georgopoulos AP, Schwartz AB, Kettner RE (1986) Neuronal population coding of movement direction. Science 233:1416-1419.

Georgopoulos AP, Lurito JT, Petrides M, Schwartz AB, Massey JT (1989) Mental rotation of the neuronal population vector. Science 243:234-236.

Gerfen CR (1985) The neostriatal mosaic. I. Compartmental organization of projections from the striatum to the substantia nigra in the rat. J Comp Neurol 236:454-476.

Gerfen CR, Young WS III (1988) Distribution of striatonigral and striatopallidal peptidergic neurons in both patch and matrix components: an in situ hybridization histochemistry and fluorescent retrograde tracing study. Brain Res 460:161-167.

Gerfen CR, Engber TM, Mahan LC, Susel Z, Chase TN, Monsma FJ $\mathrm{Jr}$, Sibley DR (1990) D1 and D2 dopamine receptor-regulated gene expression of striatonigral and striatopallidal neurons. Science 250: $1429-1432$.

Giménez-Amaya J-M, Graybiel AM (1990) Compartmental origins of the striatopallidal projection in the primate. Neuroscience 34:111126.

Giménez-Amaya J-M, Graybiel AM (1991) Modular organization of projection neurons in the matrix compartment of the primate striatum. J Neurosci 11:779-791.

Graybiel AM, Chesselet M-F (1984) Compartmental distribution of striatal cell bodies expressing met-enkephalin-like immunoreactivity. Proc Natl Acad Sci USA 81:7980-7984.

Graybiel AM, Ragsdale CW Jr (1978) Histochemically distinct compartments in the striatum of human, monkey, and cat demonstrated by acetylthiocholinesterase staining. Proc Natl Acad Sci USA 75: 5723-5726.

Graybiel AM, Hirsch EC, Agid YA (1987) Differences in tyrosine hydroxylase-like immunoreactivity characterize the mesostriatal innervation of striosomes and extrastriosomal matrix at maturity. Proc Natl Acad Sci USA 84:303-307.

Graybiel AM, Flaherty AW, Giménez-Amaya J-M (1991) Striosomes and matrisomes. In: The basal ganglia, III (Bernardi G, Carpenter MB, di Chiara G, Morelli M, Stanzione P, eds), pp 3-12. NY: Plenumm

Haber S, Elde R (1982) The distribution of enkephalin immunoreactive fibers and terminals in the monkey central nervous system: an immunohistochemical study. Neuroscience 7:1049-1095.

Hazrati L-N, Parent A, Mitchell S, Haber SN (1990) Evidence for interconnections between the two segments of the globus pallidus in primates: a PHA-L anterograde tracing study. Brain Res 533:171175.

Hikosaka O, Sakamoto M, Usui S (1989) Functional properties of monkey caudate neurons. I. Activities related to saccadic eye movements. J Neurophysiol 61:780-798.

Hirsch EC, Graybiel AM, Hersh LB, Duyckaerts C, Agid Y (1989) Striosomes and extrastriosomal matrix contain different amounts of immunoreactive choline acetyltransferase in the human striatum. Neurosci Lett 96:145-150.

Holt DJ, de Lacalle S, Saper CB (1992) Compartmentalization of cholinergic innervation of the human striatum. Soc Neurosci Abstr 18:307.
Jiménez-Castellanos J, Graybiel AM (1989) Compartmental origins of striatal efferent projections in the cat. Neuroscience 32:297-321.

Joyce JN, Sapp DW, Marshall JF (1986) Human striatal dopamine receptors are organized in compartments. Proc Natl Acad Sci USA 83:8002-8006.

Kawaguchi Y, Wilson CJ, Emson PC (1990) Projection subtypes of rat neostriatal matrix cells revealed by intracellular injection of biocytin. J Neurosci 10:3421-3438.

Kincaid AE, Newman SW, Young AB, Penney JB (1990) Evidence for a projection from the globus pallidus to the entopeduncular nucleus in the rat. Soc Neurosci Abstr 16:427.

Le Moine C, Normand E, Guitteny AF, Fouque B, Teoule R, Bloch B (1990) Dopamine receptor gene expression by enkephalin neurons in rat forebrain. Proc Natl Acad Sci USA 87:230-234.

Loopuijt LD, van der Kooy D (1985) Organization of the striatum: collateralization of its efferent axons. Brain Res 348:86-99.

Meador-Woodruff JH, Mansour A, Healy DJ, Kuehn R, Zhou Q-Y, Bunzow JR, Akil H, Civelli O, Watson SJ Jr (1991) Comparison of the distributions of $D_{1}$ and $D_{2}$ dopamine receptor mRNA in rat hrain. Neuropsychopharmacology 5:231-242.

Mesulam M-M (1978) Tetramethyl benzidine for horseradish peroxidase neurohistochemistry: a non-carcinogenic blue reaction product with superior sensitivity for visualizing neural afferents and ef ferents. J Histochem Cytochem 26:106-117.

Nastuk MA, Graybiel AM (1985) Patterns of muscarinic cholinergic binding in the striatum and their relation to dopamine islands and striosomes. J Comp Neurol 237:176-194.

Parent A, Smith Y, Filion M, Dumas J (1989) Distinct afferents to internal and external pallidal segments in the squirrel monkey. Neurosci Lett 96:140-144.

Penny GR, Afsharpour S, Kitai ST (1986) The glutamate decarboxylase-, leucine enkephalin-, methionine enkephalin- and substance $\mathbf{P}-$ immunoreactive neurons in the neostriatum of the rat and cat: evidence for partial population overlap. Neuroscience 17:1011-1045.

Ragsdale CW, Graybiel AM (1990) A simple ordering of neocortical areas established by the compartmental organization of their striatal projections. Proc Natl $\Lambda$ cad Sci USA 87:6196-6199.

Selemon LD, Goldman-Rakic PS (1990) Topographical intermingling of striatonigral and striatopallidal neurons in the rhesus monkey. $\mathrm{J}$ Comp Neurol 297:359-376.

Smith Y, Bolam JP (1990) Convergence of pallidal and striatal inputs to neurones in the entopeduncular nucleus and substantia nigra of the rat: application of a new double anterograde labeling method at electron microscopic level. Soc Neurosci Abstr 16:236.

Surmeier DJ, Eberwine J, Wilson CJ, Cao Y, Stefani A, Kitai ST (1992) Dopamine receptor subtypes colocalize in rat striatonigral neurons. Proc Natl Acad Sci USA 89:10178-10182.

Yelnik J, Francois C, Percheron G, Tande D (1991) Morphological taxonomy of the neurons of the primate striatum. J Comp Neurol 31:273-294.

Zhang WQ, Pennypacker H, Ye H, Merchenthaler IJ, Grimes L, Iadarola MJ, Hong JS (1992) A $35 \mathrm{kDa}$ Fos-related antigen is co-localized with substance $P$ and dynorphin in striatal neurons. Brain Res 577: 312-317. 